\title{
Differentiating between Information and Knowledge Flows
}

\author{
Mara Pudane \\ Riga Technical University, Kalku 1, LV-1658, Riga, Latvia \\ mara.pudane@rtu.lv
}

\begin{abstract}
Well-established knowledge and information flows are one of the main organisation success factors. It is possible to address different organisational issues by analysing knowledge and information flows, so the difference between these two types of flows has to be stated. This paper proposes a way how to differentiate between information and knowledge flows conceptually, in an organisation, and in information systems.
\end{abstract}

Keywords: Knowledge node, repository, interface.

\section{Introduction}

It is often noted that one of the most important components of successful organisation is existing information and the way it moves among workers. The one flaw with information flows is that even if an information processing node (e.g., human, computer program, or both together) has all the information it needs, there is no guarantee that the node will process it correctly. It is not enough with information availability alone; a worker (the information processing node) has to have knowledge of how to react upon the information [1].

The identification and processing of information and knowledge flows allow finding problematic areas in the circulation of information and knowledge, as well as suggesting how these problems could be solved [2], [3].

The goal of this paper is to propose one way how to practically separate knowledge and information flows. It could be beneficial for information systems (IS) architects in designing specific systems, e.g., knowledge management supporting IS. It is a potentially powerful idea that could help to develop such fields as information logistics or business analysis from a scientific point of view.

The second section focuses on the concepts of proposed idea. The third section concerns mechanisms for implementing differences between information and knowledge flows. The last section concludes the paper. 


\section{Concept of Differentiating}

Difference between information and knowledge concept is fuzzy and often neglected, yet information and knowledge flow analysis is mostly used for different reasons. For example, in [4] knowledge flows are used to determine where nodes can get the processes they need to do their job. Similarly, they are used in [1] and in [5]. Information flows, on the other hand, are used to find information needed for a process (information demand) and to organise work - similar to a workflow [8]. Thus, one can say that the information flow focuses on what to do and where to get resources, while the knowledge flow focuses on how to do it.

There have been some discussions in literature about differences between information and knowledge flows [6], [7], [8], [9]. Some researchers do not differentiate between both flow types [7], others do it, but a term "knowledge flow" can have different meanings, see, e.g., [4] and [7], [9]. The understanding of term "information flow" is clearer [8] as it is older than "knowledge flow". Most authors agree that there is a difference between two concepts and believe that it is mainly concerned with a created value [6], [9], [4]. There are very few studies [7] that focus on both types of flows from a more practical perspective - authors usually describe differences and use a more appropriate type of flow for their research.

Also, to the author's knowledge, there have been no ideas about knowledge and information flow separation in information systems because the difference so far has been unclear and, thus, it has been impossible to implement it in information systems architecture.

There are a few reasons why there should be a clearly defined difference between information and knowledge flows. First of all, there is no united terminology; this methodology could help to distinguish what is called the knowledge flow in the context of IS architecture and what - the information flow. Secondly, it could help in developing such fields as information and knowledge logistics, tying scientific ideas to more practical and usable grounds. Finally, it would be beneficial to combine information and knowledge flows in one system because it provides an opportunity to look at an enterprise from different viewpoints.

A flow is a movement from one node to another. Nodes are units which are located at both ends of the flow. The node can be anything that can process information: a human or a computer, etc. It is also important that the node is a system with inputs being processed into outputs [2], [3].

It is proposed in [2] that the difference between knowledge and information flow lies in a value given to the node. To understand whether the value is given, authors have proposed to divide nodes into two parts: interface and repository. These two parts are not meant to be divided at a physical level as in most cases it is not possible.

The interface is part of node, which processes all incoming signals (inputs) and gives reaction (outputs). Interface stores temporary data and does all work, which is seen from the outside.

The repository is part of the node where all processing procedures and interpretation models are stored [3], e.g., semantic web, activity sequence in the 
artificial node, etc. Repository is the key of how the node will understand, interpret and use incoming information.

Every incoming flow first goes through the interface. Interface processes incoming information and, if the information has a semantic value to the node itself, the repository changes. If there is no value to the node, just output is created.

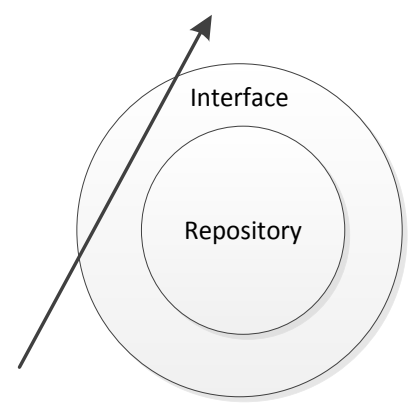

Fig. 1. (a) Information flow [3]

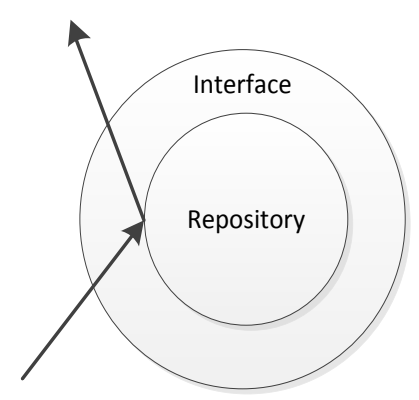

(b) Knowledge flow [3]

If the flow does not change the repository, it is the information flow, if it does - it is the knowledge flow. It is important to understand that the information flow still uses the repository to interpret incoming signals and to understand what to do next, also to understand if the incoming flow contains a value to the node (in this case the repository has to be changed). Knowledge flow changes how the knowledge node understands the surrounding environment and/or processes incoming signals.

\section{Mechanisms for Implementing Knowledge and Information Flow Difference}

Knowledge and information management systems are extremely complicated in an enterprise due to a huge number of nodes and interactions between them. Therefore, it is important to implement information and knowledge management using IS [1].

In IS the node is part of information systems architecture. As the node can contain knowledge nodes itself, interpretation depends on the level of abstraction. In one case the node can be a database, in another - one part of database, needed for a specific task.

Each node, as proposed above, can be separated into two logical parts: interface and repository, which can be identified quite clearly. Every structure, procedure, model, algorithm is knowledge that the node holds and is considered a repository. Interface is a way how a procedure or algorithm is executed. In this interpretation if there is an algorithm, implemented in a code, the change of algorithm is considered 
the knowledge flow; however, the execution of code is triggered by the information flow.

It is possible to determine similar templates in every IS part. In Table 1 it is shown how to determine whether the incoming flow is the information or knowledge flow for some of the most common IS components. For example, database query SELECT changes only data (information flow), but CREATE changes metadata and database structure (knowledge flow).

Table 1. Separation of Knowledge and Information Flows

\begin{tabular}{|c|c|c|c|}
\hline Part of IS & $\begin{array}{l}\text { Incoming } \\
\text { Flow }\end{array}$ & $\begin{array}{l}\text { Information } \\
\text { Elements }\end{array}$ & $\begin{array}{l}\text { Knowledge } \\
\text { Elements }\end{array}$ \\
\hline $\begin{array}{l}\text { Data Base } \\
\text { Management } \\
\text { System }\end{array}$ & Queries & $\begin{array}{l}\text { DELETE, UPDATE, } \\
\text { INSERT, SELECT }\end{array}$ & $\begin{array}{l}\text { CREATE } \\
\text { PROCEDURE/ } \\
\text { TABLE, ADD }\end{array}$ \\
\hline Expert System & Commands & Requests & $\begin{array}{l}\text { Additions to knowledge } \\
\text { base }\end{array}$ \\
\hline $\begin{array}{l}\text { Workflow } \\
\text { Management } \\
\text { System }\end{array}$ & Notices & Routine notices & $\begin{array}{l}\text { Notices of change in } \\
\text { workflow }\end{array}$ \\
\hline
\end{tabular}

To implement this method the author suggests adding a plug-in for each information system component. Incoming flows should be checked, counted and grouped.

\section{Discussion and Conclusion}

In this paper the author has proposed a method of differentiating between knowledge and information flows in information systems.

The proposed approach can be further applied to tools that use knowledge and information flow analysis for problem identification and solving. There are many problems that could be solved or at least identified using the analysis of knowledge and information flows in an organisation. Also, this method could improve the readability of documents and help organisations to document processes better. The approach could benefit from the research of information and knowledge channels.

The paper is written as a position paper. The concepts presented here should be researched further and implemented, and tested.

Acknowledgement: The presented work was supported by National Research Programme "Development of innovative multi-functional materials, signal processing and information technology for competitive science-intensive products" fifth project "New information technologies based on ontologies and transformation". 


\section{References}

1. Dalkir, K.: Knowledge management in theory and practice, Elsevier, 345 p. (2005)

2. Zhuge H.: Knowledge flow network planning and simulation, Decision Support Systems, vol. 42 (no. 2), pp. 571-592 (2006) http://dx.doi.org/10.1016/j.dss.2005.03.007

3. Pudane M.: Information System Models for Overcoming Knowledge Flow Barriers, Bachelor thesis, Riga Technical University, Riga, Latvia, 55 p. (2011)

4. Tippmann, E., Sharkey Scott, P., Mangematin V.: Subsidiary managers' knowledge mobilizations: Unpacking emergent knowledge flows, Journal of World Business, Elsevier (2013)

5. Johansson, M., Jonsson A.: The package logic: A study on value creation and knowledge flows, European Management Journal, vol. 30(6), pp. 535-551, Elservier (2012)

6. Zhuge, H.: A knowledge flow model for peer-to-peer team knowledge sharing and management, Expert Systems with Applications, vol. 23(4), p. 23-30 (2002) http://dx.doi.org/10.1016/S0957-4174(02)00024-6

7. Caldeira Pedroso M., Nakano D.: Knowledge and information flows in supply chains: A study on pharmaceutical companies, International Journal of Production Economics, vol. 122(1), pp. 376-384 (2009)

http://dx.doi.org/10.1016/j.ijpe.2009.06.012

8. Durugbo, C., Tiwari, A., Alcock, J.: Modelling information flow for organisations: A review of approaches and future challenges, International Journal of Information Management, vol. 33(3), p. 597-610 (2013) http://dx.doi.org/10.1016/j.ijinfomgt.2013.01.009

9. Lee, H., Kim J.: Mining knowledge demands from information flow, Expert Systems with Applications, vol. 39 (8), pp. 6799-680615 (2012)

http://dx.doi.org/10.1016/j.eswa.2011.12.045 